\title{
Changes in Space Usage Behaviours after the Implementation of Seoul's Bus Rapid Transit Project in Jongno Street: A Social Data Analysis
}

\author{
Youngjin Kim ${ }^{1}$, Sunghee Lee ${ }^{1}$, Jihye $\mathrm{Gil}^{2}$, and Yonghoon $\mathrm{Son}^{3 *}$ \\ 1 Interdisciplinary Program in Landscape Architecture, Seoul National University \\ 2 Visiting Researcher, Environmental Planning Institute, Seoul National University \\ 3 Graduate School of Environmental Studies, Seoul National University \\ *Corresponding Author,Email: sonyh@snu.ac.kr
}

Received: Sept 4, $2021 \quad$ Accepted: Nov 25, 2021

Key words: Bus rapid transit, Public transport, Visitors' perception, Blog post, Text mining

\begin{abstract}
This study analysed blog data to examine visitors' behavioural changes following the introduction of a bus rapid transit (BRT) system in Seoul to vitalise public transport. Using blog texts, we assessed the appearance frequency of numerous keywords, including "Jongno Street" (the target location), "public transportation,", and "bus-only lane", to identify and categorise frequently visited places and examine the changes in user behaviours before and after project implementation. Based on this analysis, we categorised the significant places into nine types (public spaces, cultural and religious places, open spaces, major places, historic sites, streets, and structures) in accordance with Jongno's attributes. We found that the scope of visitors' activities increased within a $1-\mathrm{km}$ radius of the bus station and most people visited open spaces, streets, and major places and engaged in various activities before reaching their final destination. The visitors who used public transport often walked to their destinations within a $1-\mathrm{km}$ radius. This showed that the BRT system implemented on Jongno Street contributed to the creation of a vigorous, walkable urban environment.
\end{abstract}

\section{INTRODUCTION}

Urban development has numerous adverse effects, such as environmental pollution and traffic jams. A significant and effective solution to such issues is the promotion of public transport services. Accordingly, Levinson et al. (2003) suggested the implementation of bus rapid transit (BRT), a transport method that is flexible, fast and efficient. To date, many countries have implemented BRT systems because these systems have environmental benefits, since they reduce the number of privately owned vehicles on the road, and economic benefits, since they have lower installation-related construction costs than railway transport systems (Wirasinghe et al., 2013). Many studies have examined the effectiveness of BRTs in relieving urban traffic problems and measured their economic feasibility and efficiency (Cervero \& Dai, 2014; Deng \& Nelson, 2011; Wirasinghe et al., 2013). Overall, BRTs can increase pedestrian flow and invigorate the local 
economy. Further, BRT stations are usually built around tourist attractions where transport demands are high (Dimitriou \& Gakenheimer, 2011). To clarify public transport's capacity to improve urban mobility, (Knowles, 2012) studied BRT planning and construction in relation to urban revitalisation. However, only a few studies have analysed the changes in people's space usage behaviours that occur after BRT project implementation.

Hence, we aimed to investigate how such behaviours changed after the implementation of a BRT project within the $2.8-\mathrm{km}$ section of Seoul's Jongno Street, the last section of the BRT project that the City of Seoul had been striving to complete since 2004. Although conflicts between the nearby commercial district and the stakeholders regarding the project's commercially detrimental effects hindered its progress, the City of Seoul completed the BRT project in January 2018. We analysed the blog entries of people who visited places surrounding the project area and interpreted the distinctive attributes that appeared before and after the completion of the BRT system in Jongno to determine the behavioural changes in people's space usage.

\section{LITERATURE REVIEW}

\subsection{Seoul's BRT System and Trends in BRT Research}

During the past 50 years, Seoul has experienced rapid urbanisation and a sharp increase in population. In addition, due to an increase in incomes per capita, the number of privately owned vehicles has increased, resulting in frequent occurrences of traffic congestion. To promote the use of public transport, Seoul launched a large-scale bus system reform in July 2004, which changed the privately managed bus operation system to a public cooperative system that comprehensively manages routes, schedules and bus fares (Jun et al., 2015). For example, the city promoted user convenience by introducing a Smart Pay Card that integrated buses and the metro into the distance-based fare system.

Starting with Gangnamdaero in 2004, the City of Seoul launched a radially patterned BRT project that introduced exclusive median bus lanes, advanced bus stops, an intersection traffic signal priority system and a realtime information service for users. In 2018, this BRT network system was launched in Jongno Street. Comparisons of traffic speeds before and after the BRT opening revealed that regular vehicle speed decreased by $36 \%(5.0$ $\mathrm{km} / \mathrm{h})$, whereas the speed of buses increased by $33 \%(4.0 \mathrm{~km} / \mathrm{h})$, which shortened passengers' travel time. Similarly, passenger comparisons between January 2017 and January 2018 showed that the number of metro passengers decreased by $3 \%(180,255$ people), whereas that of bus passengers increased by $12.9 \%$ (181,183 people), which reveals that the dispersion of visitors' modes of transport near Jongno Street relieves metro congestion. Hence, Seoul is planning to further expand on the existing $126.6 \mathrm{~km}$ of bus-only lanes.

BRTs can replace some modes of public transport at a lower cost than the railway systems operated by Seoul Metro. Further, they can reduce the number of cars in the city, which, in turn, reduces $\mathrm{CO} 2$ emissions (Combs \& Rodríguez, 2014). Various studies have examined the different aspects of BRT implementation, including BRT's ability to increase real estate values 
(Cervero \& Kang, 2011; Rodríguez \& Mojica, 2009), measurements of BRT ridership (Deng \& Nelson, 2011; Jun et al., 2015; Salon, Wu, \& Shewmake, 2014), changes in land use following the establishment of a BRT (Bocarejo S. \& Oviedo H., 2012) and issues of BRT-centred urban development (Thomas \& Deakin, 2008).

A few studies have comprehensively examined passengers' perceptions of and views on public transport systems. Although some transport studies have utilised social media data (Bregman, 2012; Casas \& Delmelle, 2017; Chan \& Schofer, 2014), most have analysed people's emotional sentiments regarding different modes of transport (Collins, Hasan, \& Ukkusuri, 2013; Gal-Tzur et al., 2014; Grant-Muller et al., 2015).

\subsection{Public Transport and Community Vitalisation}

Increased connectivity in urban public transport can reduce spatial inequality and increase accessibility to public services (Chang et al., 2019). The relationship between public transport and community vitalisation is intricate; furthermore, public transport enhances accessibility to markets, increases community flexibility, and improves the local economy's productivity and competitiveness (Jackson et al., 2015; Wegener, 2011). Furthermore, although transport systems, including privately owned vehicles, positively affect the economy and the growth of other industries, they have significant negative effects on society since they increase exhaust gas volumes, cause heavy traffic and result in higher energy consumption (Elhaji \& Ochieng, 2020). Therefore, establishing new policies or building infrastructure for public transport can help create sustainable cities from economic, social and environmental perspectives (Mahmoudi et al., 2019).

\subsection{Use of Blog Text Data}

Big data analyses of texts from online web pages containing a large quantity of information enable effective assessments and minimise the interference of subjectivity that is associated with conventional qualitative research methods (Guo et al., 2016; Hannigan, 2015; Matthies \& Coners, 2015; Moreno \& Redondo, 2016). Through text mining, one can examine the relationship among words and sentences and derive a text's intended meaning (Hotho, Nürnberger, \& Paass, 2005). This method has numerous benefits, one of which is that it can be used to analyse a large volume of text data more quickly and provide more objective and significant information than conventional research methods (Daniel, 2015; Guo et al., 2016; Hannigan, 2015; Matthies \& Coners, 2015; Moreno \& Redondo, 2016; Zakir, Seymour, \& Berg, 2015). The blog data used in this study contain descriptions of various information and texts reflecting the daily events that were considered important by users. Since bloggers express their thoughts and sentiments on a certain topic (Jang, Kim, \& Rhee, 2012; Lee \& Son, 2018), most blog entries contain photographs and texts describing individuals' opinions of certain places, which are based on their experience (Lee \& Chung, 2014). Hence, blogs are convenient data sets that can help researchers understand users' subjective views on places (Lee \& Son, 2018). In addition, since the views of the public on transport modes can differ from those of experts, understanding users' experiences is a significant aspect of the management of transport systems. 


\section{RESEARCH METHODS}

\subsection{Research Target Area}

As shown in Figure 1, we selected a $2.8-\mathrm{km}$ section of Jongno Street, located at the centre of the radial-patterned BRT project. The project has encountered many challenges due to pre-existing road and traffic conditions and conflicts among stakeholders. Jongno Street is home to diverse institutions and places, including historic, cultural and industrial sites, and consists of six districts, some of which contain several United Nations Educational, Scientific and Cultural Organization (UNESCO) cultural heritage sites, such as the Jongmyo Shrine and Changdeokgung Palace, as well as markets, industrial facilities, cultural facilities, food alleys and business headquarters.

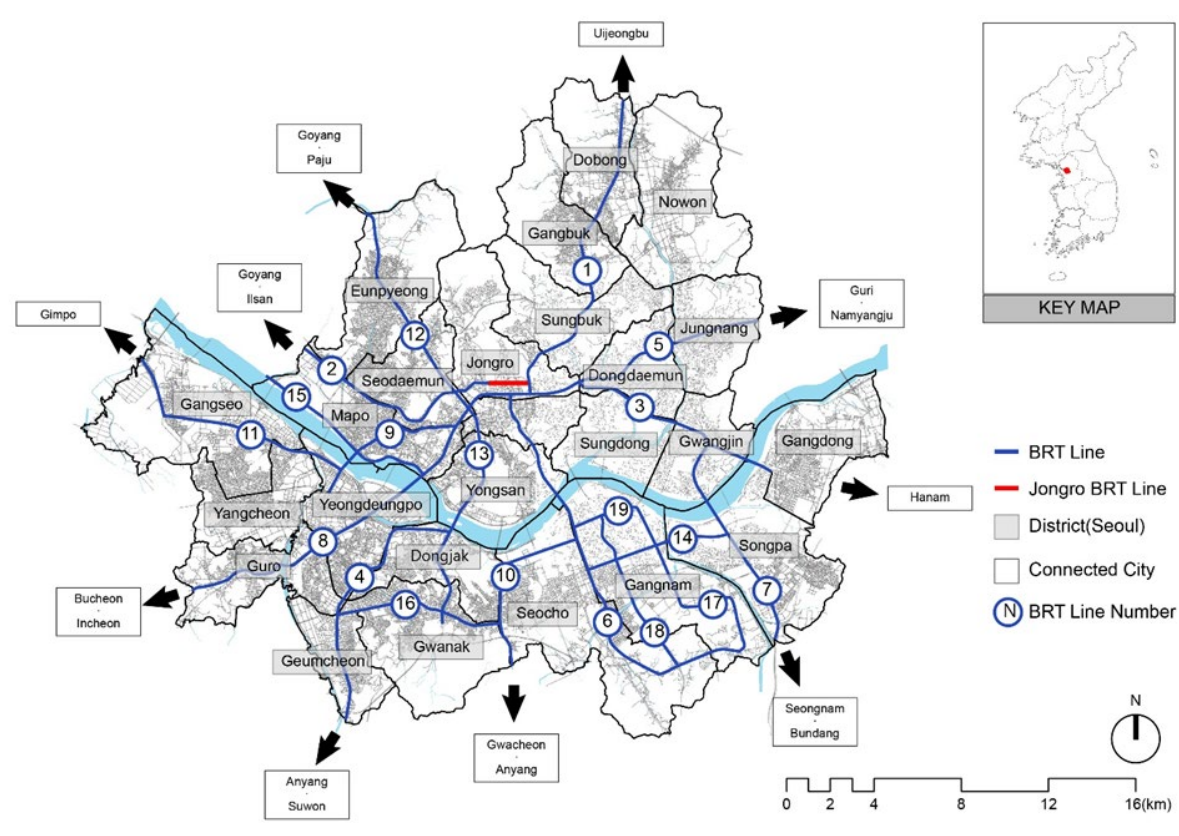

Figure 1. BRT routes in Seoul

\subsection{Data Collection}

To understand the changes in visitor behaviours on Jongno Street after BRT implementation, we performed the analysis shown in Figure 2. To collect text data, we examined blog posts on the Korean portal sites Naver (https://blog.naver.com) and Daum (https://blog.daum.net). To determine the relevant blog posts, we used a combination of the following keywords: "Jongno 1st-6th Streets", "public transportation,", "bus-only lane" and "median lane". To analyse the differences before and after BRT implementation, we selected blog posts written during the span of one year, from 2017 to 2018. Table 1 indicates the volume of collected data. Abstracted texts were considered more useful to this study than complete texts, since the former enabled us to obtain data more easily by focusing on the keywords used for analysis. 


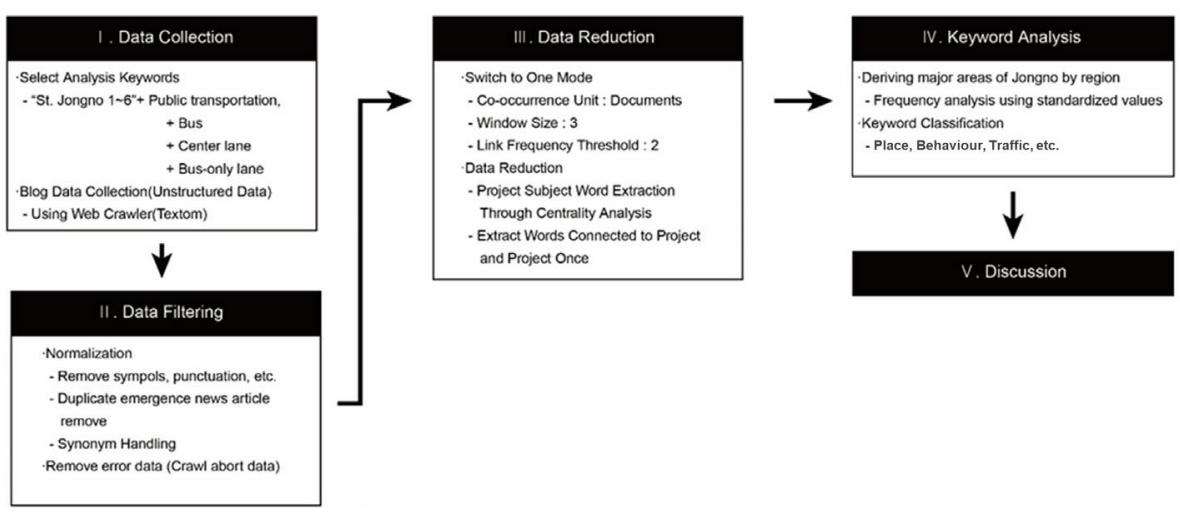

Figure 2. Data processing and analysis methods used in the study

Table 1. Volume of data collected from Jongno Street by area and project period

\begin{tabular}{llll}
\hline Jongno & & \multicolumn{2}{l}{ Crawling Data } \\
\cline { 3 - 4 } $\begin{array}{l}\text { Street } \\
\text { No. }\end{array}$ & Project Time (Before/After) & Search Volume & Collected Data \\
\hline \multirow{2}{*}{$1^{\text {st }}$} & Before & 2,654 & 2,371 \\
& After & 2,558 & 2,529 \\
\multirow{2}{*}{$2^{\text {nd }}$} & Before & 3,303 & 2,592 \\
& After & 2,784 & 1,896 \\
$3^{\text {rd }}$ & Before & 8,003 & 3,600 \\
& After & 7,453 & 3,752 \\
$4^{\text {th }}$ & Before & 2,074 & 1,942 \\
& After & 2,275 & 1,942 \\
$5^{\text {th }}$ & Before & 4,155 & 2,786 \\
& After & 4,577 & 2,573 \\
$6^{\text {th }}$ & Before & 1,135 & 1,091 \\
& After & 1,499 & 1,417 \\
\hline
\end{tabular}

\subsection{Analysis Method: Data Cleaning and Reduction}

Sentence-type data, such as those collected from blogs, are unstructured content. A cleaning and reduction process must be performed to reformulate the content into an easy format for analysis (Karl, Wisnowski, \& Rushing, 2015; Lucas et al., 2015). In the pre-treatment process of data cleaning, we eliminated unnecessary special characters and punctuation marks from the blog data and categorised words with similar meanings as synonyms. To extract keywords on Jongno Street's BRT project and reduce the data, we calculated the degree centrality of data by selecting the neighbouring nodes connected to each of the following keyword nodes: "public transportation,", "bus" and "bus-only lane". In general, term frequency-inverse document frequency (TF-IDF) is used in keyword analyses. However, the use of TFIDF in analysing new concepts or proper nouns can underestimate or overestimate a keyword's importance (Lim \& Park, 2015). Therefore, we 
calculated the term frequency (TF). Finally, we used NetMiner 4.0 to analyse the collected blog data.

\section{RESULTS AND DISCUSSION}

\subsection{Places in Jongno Street Mentioned in the Blogs}

To understand the attributes of the frequently visited places on Jongno Street, we analysed the frequently occurring keywords in the collected blog data. Subsequently, we examined and compared keyword frequencies before and after the establishment of the Jongno BRT (Table 2). Specifically, from the top 100 overlapping terms among the 1,000 keywords extracted from blog data, we selected some words that were not closely related to the BRT project, for example, "holiday", "time" and "building structure". The differences in frequency of these words before and after the establishment of the Jongno BRT were not significant. In other words, the comparative analysis of the increases and decreases in frequency of keyword appearances related to the BRT showed valid differences. Therefore, the comparative analysis results were used to determine the frequency of BRT user visits to certain places.

Table 2. Keyword differences in data collected from Jongno before and after BRT construction

\begin{tabular}{l|c|c|c|c|c|c|c|c|c|c|c|c|c|c|c|c|c|c}
\hline \multirow{2}{*}{ Keywords } & \multicolumn{3}{|c|}{ Jongno $1^{\text {st }}$ Street } & \multicolumn{2}{|c|}{ Jongno $2^{\text {nd }}$ Street } & \multicolumn{2}{c|}{ Jongno $3^{\text {rd }}$ Street } & \multicolumn{2}{|c|}{ Jongno $4^{\text {th }}$ Street } & \multicolumn{2}{|c|}{ Jongno $5^{\text {th }}$ Street } & \multicolumn{3}{|c}{ Jongno $6^{\text {th }}$ Street } \\
\cline { 2 - 7 } & BF & AF & DF & BF & AF & DF & BF & AF & DF & BF & AF & DF & BF & AF & DF & BF & AF & DF \\
\hline Use & 215 & 208 & -7 & 231 & 211 & -20 & 659 & 809 & 150 & 206 & 202 & -4 & 425 & 406 & -19 & 103 & 66 & -37 \\
\hline Time & 88 & 92 & 4 & 164 & 88 & -76 & 224 & 227 & 3 & 95 & 71 & -24 & 139 & 126 & -13 & 54 & 45 & -9 \\
\hline Structure & 65 & 105 & 40 & 145 & 125 & -20 & 123 & 135 & 12 & 58 & 59 & 1 & 129 & 112 & -17 & 18 & 17 & -1 \\
\hline Photo & 56 & 36 & -20 & 47 & 51 & 4 & 98 & 67 & -31 & 25 & 22 & -3 & 69 & 91 & 22 & - & - & - \\
\hline Internet & 56 & 46 & -10 & 78 & 41 & -37 & 101 & 113 & 12 & 46 & 30 & -16 & 91 & 71 & -20 & 24 & 18 & -6 \\
\hline Holiday & 45 & 76 & 31 & 71 & 96 & 25 & 79 & 157 & 78 & 52 & 71 & 19 & 70 & 119 & 49 & - & - & - \\
\hline Guide & 41 & 32 & -9 & 37 & 36 & -1 & 82 & 84 & 2 & - & - & - & 41 & 40 & -1 & 22 & 13 & -9 \\
\hline Perimeter & 36 & 35 & -1 & - & - & - & 85 & 63 & -22 & 28 & 40 & 12 & 41 & 55 & 14 & - & - & - \\
\hline Family & 31 & 21 & -10 & 67 & 30 & -37 & 102 & 111 & 9 & 42 & 41 & -1 & 91 & 103 & 12 & 15 & 23 & 8 \\
\hline Region & 35 & 50 & 15 & 42 & 32 & -10 & 67 & 57 & -10 & 30 & 43 & 13 & - & - & - & - & - & - \\
\hline Telephone & 28 & 28 & 0 & 88 & 49 & -39 & 62 & 74 & 12 & 52 & 24 & -28 & 56 & 36 & -20 & 19 & 7 & -12 \\
\hline School & - & - & - & 147 & 122 & -25 & 99 & 142 & 43 & 109 & 93 & -16 & 156 & 149 & -7 & 46 & 30 & -16 \\
\hline Special & - & - & - & 112 & 98 & -14 & - & - & - & 63 & 78 & 15 & 45 & 36 & -9 & 23 & 25 & 2 \\
\hline Today & - & - & - & 53 & 43 & -10 & 105 & 80 & -25 & 27 & 35 & 8 & 70 & 56 & -14 & - & - & - \\
\hline Image & - & - & - & 56 & 33 & -23 & 93 & 88 & -5 & 28 & 38 & 10 & 73 & 69 & -4 & - & - & - \\
\hline
\end{tabular}

Note: BF: Before-the-project keyword frequency; AF: after-the-project keyword frequency; DF: difference

We extracted 276 place lexemes referring to major places on Jongno Street (Figure 3) and categorised visitors' keywords into nine types according to these spaces' characteristics and locations (Table 3). Jongno's 1 st Street is a major dense business district. BRT users visited commercial and business facilities (financial institutions and enterprises), public facilities (the City Hall, Post Office, Jongno District Office and Constitutional Court), open spaces (Gwanghwamun Plaza, Cheonggye Plaza and Seoul Plaza) and a waterfront site (Cheonggye Stream), as well as some historic sites 
(Gyeongbokgung Palace and Deoksugung Palace) that are popular tourist attractions in South Korea. Jongno's 2nd Street mainly comprises open spaces (e.g., Tapgol Park, which is popular among the elderly), roads (e.g., Insa-dong Street, Myeong-dong Street and Youth Street, which are also famous tourist attractions), commercial and business facilities (famous restaurants, cafes and beauty salons) and major places.

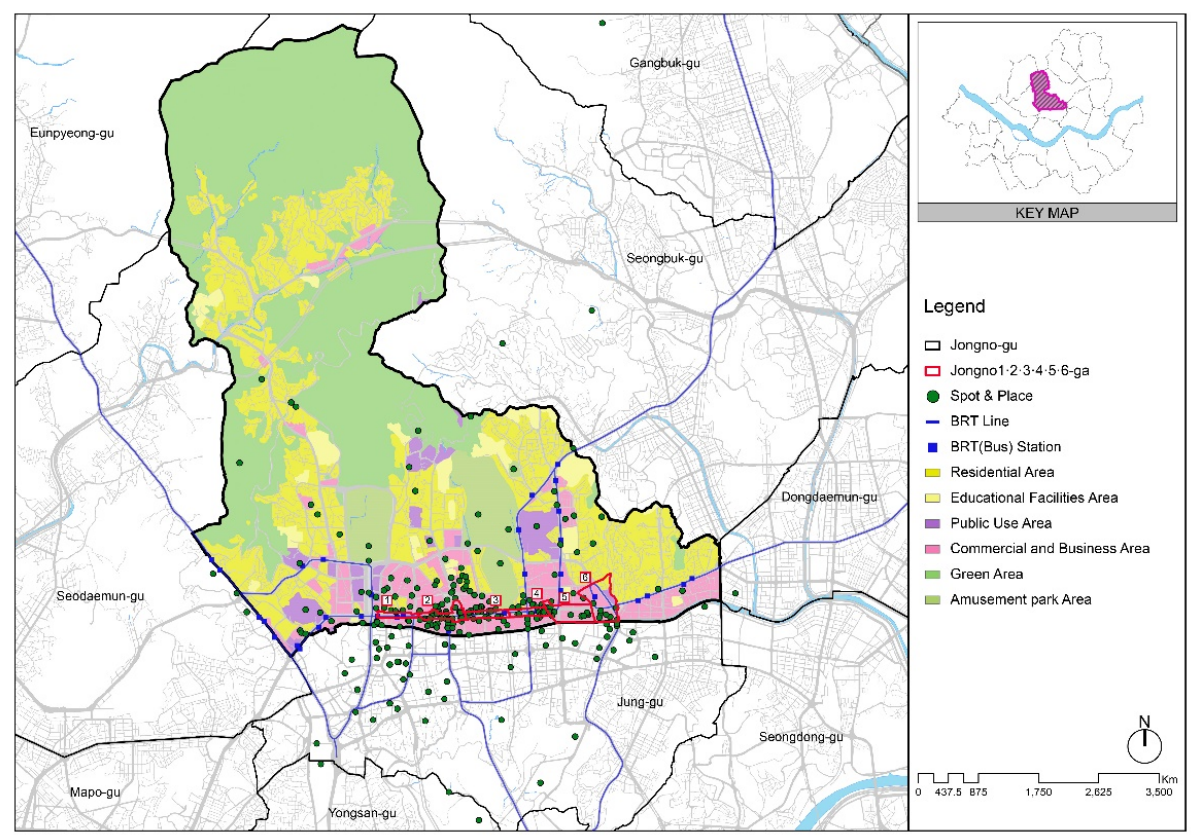

Figure 3. Places to visit in Jongno

Table 3. Places visited by people using public transport in Jongno

\begin{tabular}{|c|c|c|c|c|c|c|c|c|c|c|}
\hline \multirow[b]{2}{*}{ Places } & \multicolumn{10}{|c|}{ Division } \\
\hline & $\begin{array}{c}\text { Public } \\
\text { Facilities }\end{array}$ & $\begin{array}{c}\text { Commercial } \\
\text { and Business } \\
\text { Facilities }\end{array}$ & $\begin{array}{c}\text { Traffic } \\
\text { Facilities }\end{array}$ & $\begin{array}{c}\text { Cultural } \\
\text { and } \\
\text { Religious } \\
\text { Facilities }\end{array}$ & $\begin{array}{c}\text { Open } \\
\text { Spaces }\end{array}$ & $\begin{array}{l}\text { Major } \\
\text { Places }\end{array}$ & $\begin{array}{c}\text { Historic } \\
\text { Sites }\end{array}$ & Streets & Structure & Total \\
\hline $1^{\text {st }}$ & 10 & 27 & 1 & 8 & 7 & 5 & 20 & 1 & 10 & \\
\hline $2^{\text {nd }}$ & 13 & 61 & 1 & 13 & 10 & 8 & 23 & 5 & 3 & \\
\hline $3^{\text {rd }}$ & 11 & 58 & 2 & 15 & 10 & 8 & 23 & 5 & 1 & \\
\hline $4^{\text {th }}$ & 8 & 31 & 2 & 9 & 5 & 5 & 19 & 1 & 3 & \\
\hline $5^{\text {th }}$ & 9 & 47 & 1 & 10 & 11 & 6 & 17 & 2 & - & \\
\hline $6^{\text {th }}$ & 6 & 24 & 1 & 7 & 6 & 3 & 14 & - & 2 & \\
\hline $\begin{array}{l}\text { Jongno's } \\
\text { Extracted } \\
\text { Places }\end{array}$ & 23 & 153 & 2 & 25 & 13 & 10 & 29 & 5 & 16 & 276 \\
\hline
\end{tabular}

Jongno's 3rd Street comprises cultural and religious facilities (performing arts centres and cinemas), commercial and business facilities (restaurants, cafes and jewellery stores) and historic sites (Jongmyo Shrine and Changgyeonggung Palace, both of which are UNESCO World Cultural Heritage sites). Further, Jongno's 4th and 5th Streets both feature commercial and business facilities that are mentioned in the blogs. Jongno's 4th Street includes commercial buildings (Sewoon Plaza and Sewoon 
Square) that sell various electronic goods, and large-scale buildings that sell precious metals and jewellery. Contrastingly, Jongno's 5th Street contains markets (Gwangjang Market, Bangsan Market, Dongdaemun Market and Shinjin Market), which house several restaurants and cafes.

Finally, Jongno's 6th Street comprises several commercial and business facilities (outlets, shopping malls and markets: Dongdaemun Market, Pyeonghwa Market and Jongno Street Flower Market), cultural and religious facilities, and open spaces (Dongdaemun Fortress Park and Dongdaemun History and Culture Park). Within this street, the Dongdaemun Design Plaza is considered the main place to visit and has been featured in blogs as a local landmark. In other words, the blog data indicated that various places and spots along Jongno Street can be categorised as commercial and business facilities, historic sites, and landmarks.

\subsection{User Behaviours Before and After the Opening of the BRT}

We analysed behavioural changes among visitors to Jongno's 4th Street, which has no metro stations nearby, to clarify the BRT system's impact on the surrounding area. Further, we limited the investigation scope to the places located within a $1-\mathrm{km}$ radii of the BRT station. As shown in Table 4 and Figure 4, the blog data analysis conducted before and after the opening of the BRT revealed either increases or decreases in the frequency of visits to places on Jongno's 4th Street within 500-m and 1-km radii. Regarding the places that showed frequency disparities, we selected those with a minimum frequency difference of $10 \%$ based on keyword hierarchy analysis.

Table 4. Places visited in Jongno's 4th Street before and after BRT system construction

\begin{tabular}{|c|c|c|c|c|c|c|c|c|}
\hline \multirow[b]{2}{*}{ Radius } & \multirow[b]{2}{*}{ Division } & \multirow[b]{2}{*}{$\begin{array}{l}\text { Number } \\
\text { of Places } \\
\text { and Spots }\end{array}$} & \multirow[b]{2}{*}{$\begin{array}{l}\text { In- } \\
\text { crease }\end{array}$} & \multirow[b]{2}{*}{$\begin{array}{l}\text { Main- } \\
\text { tenance }\end{array}$} & \multirow[b]{2}{*}{$\begin{array}{l}\text { De- } \\
\text { crease }\end{array}$} & \multicolumn{3}{|c|}{ Frequency } \\
\hline & & & & & & $\begin{array}{l}\text { Before } \\
\text { the } \\
\text { Project } \\
\text { (A) } \\
\end{array}$ & $\begin{array}{l}\text { After the } \\
\text { Project } \\
\text { (B) }\end{array}$ & $\begin{array}{l}\text { Diffe- } \\
\text { rence } \\
(B-A)\end{array}$ \\
\hline \multirow{6}{*}{$500 \mathrm{~m}$} & Historic Sites & 1 & 1 & - & - & 294 & 347 & 53 \\
\hline & $\begin{array}{l}\text { Commercial and } \\
\text { Business } \\
\text { Facilities }\end{array}$ & 37 & 14 & 3 & 20 & 1,104 & 1,004 & -100 \\
\hline & Public Facilities & 4 & - & - & 4 & 56 & 27 & -29 \\
\hline & $\begin{array}{l}\text { Cultural and } \\
\text { Religious } \\
\text { Facilities }\end{array}$ & 3 & - & - & 3 & 29 & 16 & -13 \\
\hline & Traffic Facilities & 1 & - & - & 1 & 6 & 5 & -1 \\
\hline & Total & 46 & 15 & 3 & 28 & 1,489 & 1,399 & -90 \\
\hline \multirow{6}{*}{$\begin{array}{l}500 \mathrm{~m} \\
\text { to } 1 \mathrm{~km}\end{array}$} & Open Spaces & 1 & 1 & - & - & 50 & 228 & 178 \\
\hline & Major Places & 4 & 1 & - & 3 & 222 & 306 & 84 \\
\hline & Historic Sites & 3 & 1 & - & 2 & 329 & 283 & -46 \\
\hline & $\begin{array}{l}\text { Commercial and } \\
\text { Business } \\
\text { Facilities }\end{array}$ & 53 & 19 & 11 & 23 & 291 & 353 & 62 \\
\hline & Public Facilities & 6 & 1 & - & 5 & 40 & 28 & -12 \\
\hline & $\begin{array}{l}\text { Cultural and } \\
\text { Religious } \\
\text { Facilities }\end{array}$ & 6 & 3 & - & 3 & 61 & 97 & 36 \\
\hline
\end{tabular}




\begin{tabular}{l|l|r|r|r|r|r|r|r}
\hline Street & & 2 & 2 & - & - & 6 & 16 & 10 \\
\cline { 2 - 9 } Structure & & 1 & - & - & 1 & 4 & - & -4 \\
\cline { 2 - 9 } & Total & 78 & 28 & 15 & 35 & 1,003 & 1,311 & 308 \\
\hline
\end{tabular}

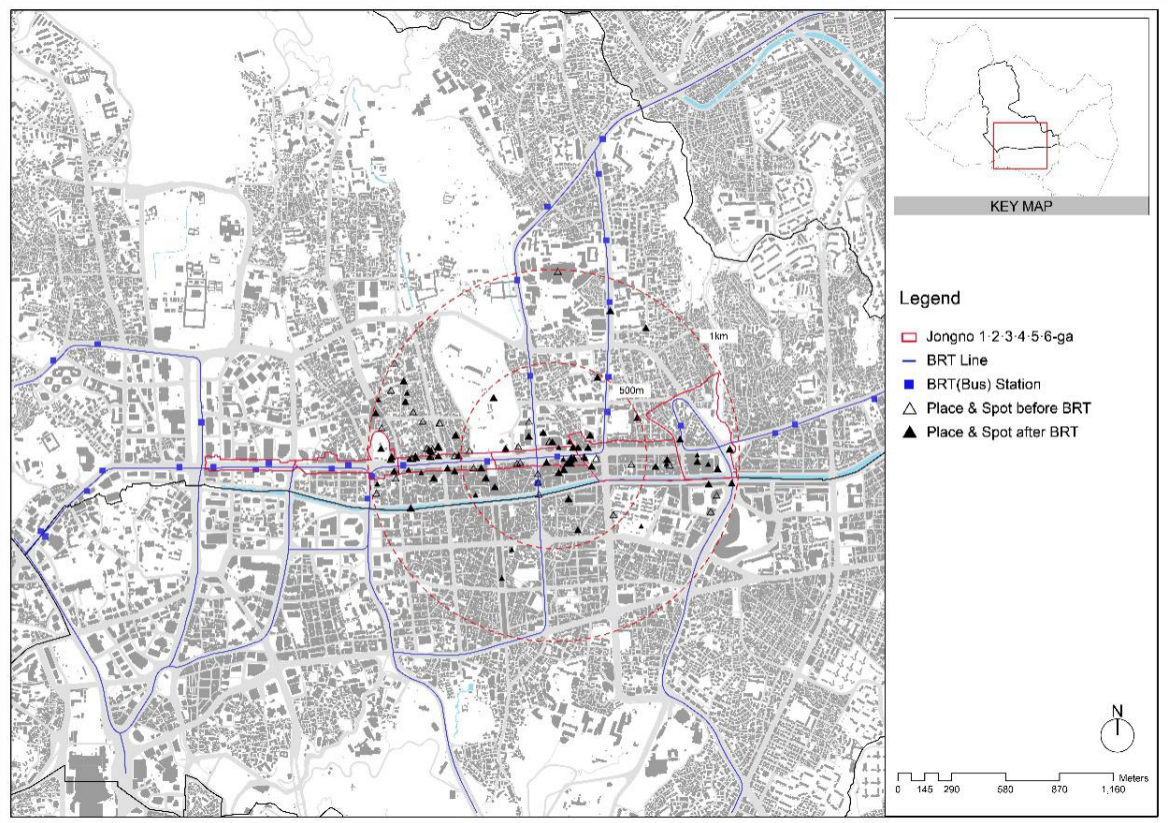

Figure 4. Differences in the frequency of places that appeared around Jongno 4th

Among the 46 places located within a 500-m radius of the BRT station, keyword frequency increased for the Jongmyo Shrine (historic site) and decreased for the following places: Doosan Art Centre and Atrium (cultural and religious facilities), Jongmyo Shrine Public Carpark (traffic facilities), post offices and medical facilities (public facilities), and Gwangjang Market and Flea Market (markets). For commercial and business facilities, the results revealed both frequency decreases (wedding halls and jewellery shops) and increases (food and beverage shops, Boseong Shopping Complex, Sewoon Plaza, convenience stores and banks). The decrease in the frequency of keywords related to commercial and business facilities is a direct consequence of moving a particular type of business (jewellery business) to a large-scale shopping centre, rather than placing it among scattered locations on Jongno's 4th Street. Furthermore, the frequency of keywords used to find markets decreased, whereas the frequency of keywords related to the restaurants and cafes within these markets increased.

Overall, we found a decreasing tendency in the frequency of keywords used that refer to place names within a 500-m radius of the BRT station. This result is inconsistent with the findings of earlier studies, which suggest that BRT stations have a positive impact on the value and activity of real estate within a 300- to 500-m radius of the stations (Cervero \& Kang, 2011; Mulley \& Tsai, 2016; Rodríguez \& Mojica, 2009; Rodríguez \& Targa, 2004). Furthermore, our results revealed that BRT stations increase visitors' accessibility to their final destination and invigorate the businesses along the route while lowering the frequency of visits to the surrounding commercial buildings. In this sense, the frequency of keywords that named the places located between $500-\mathrm{m}$ and $1-\mathrm{km}$ radius tended to increase (Figure 5 and Figure 6). The final destinations, such as city parks, historic sites and popular commercial buildings, were located within this $1-\mathrm{km}$ radius. Specifically, among the 78 places that were identified, we found an increase 
in frequency for the following types: open spaces (Tapgol Park), historic and fancy streets (Ikseon-dong), cultural and religious facilities (performing arts centres and cinemas), and streets (Jewellery Street and Monkfish Stew Street). However, this frequency decreased for the following space types: historic sites (Dongdaemun) and public facilities (the tax office, as well as the police station and post office on Jongno's 2nd Street).

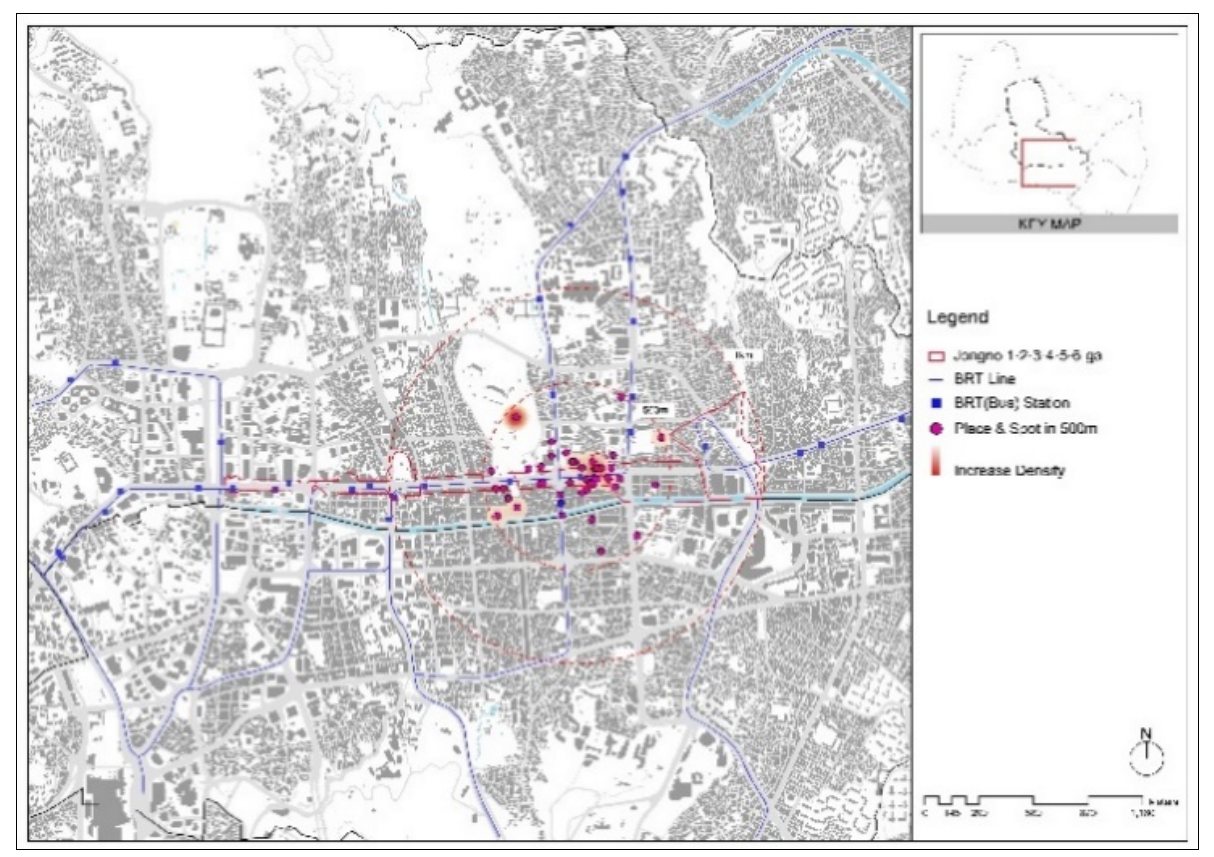

Frequency Increase in Areas Located within $500 \mathrm{~m}$

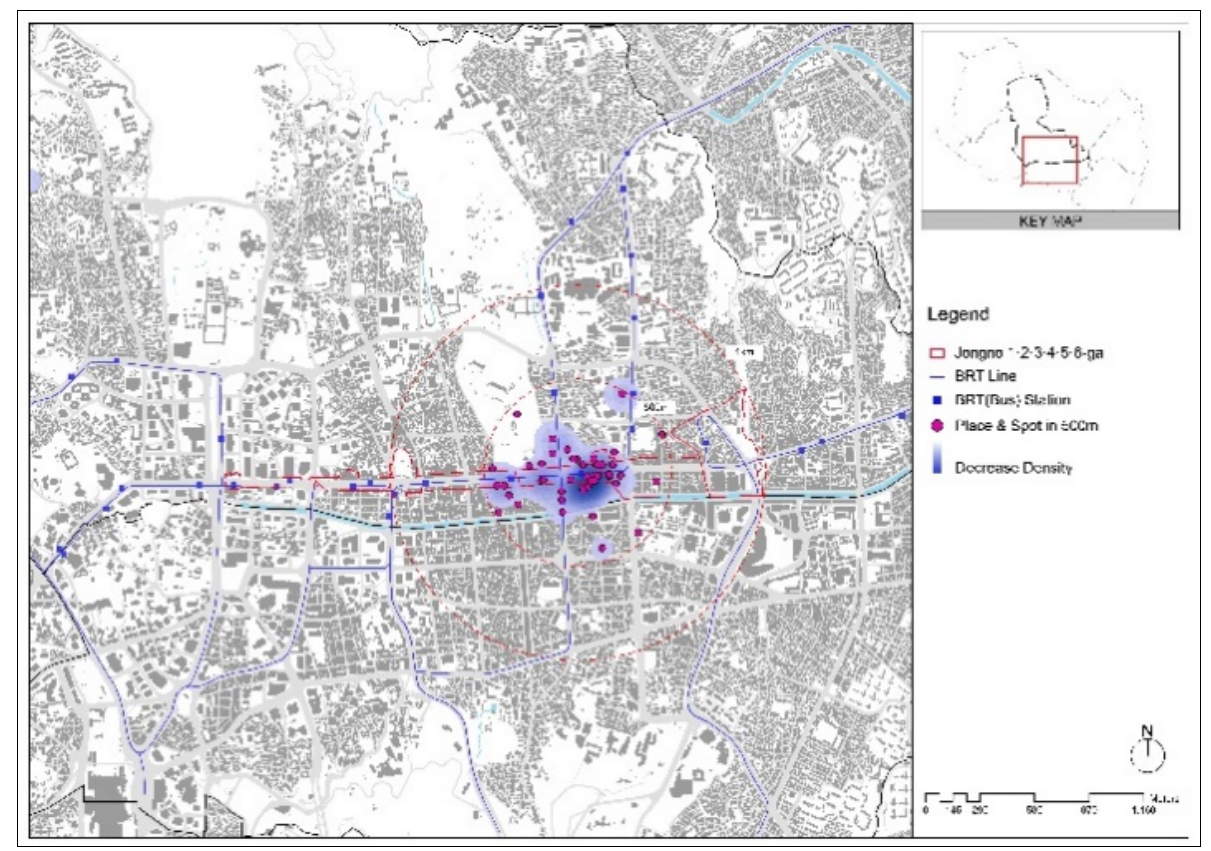

Frequency Decrease in Areas Located within 500 m

Figure 5. Frequency variations of places according to $0-500 \mathrm{~m}$ distance from the station

For commercial and business facilities, the overall frequency increased, particularly for restaurants and cafes that presented characteristic changes in their business types. Furthermore, the results revealed an increase in the 
frequency of keywords searching for walkable places, including open spaces, major places, and streets within a $1-\mathrm{km}$ radius of the BRT station.

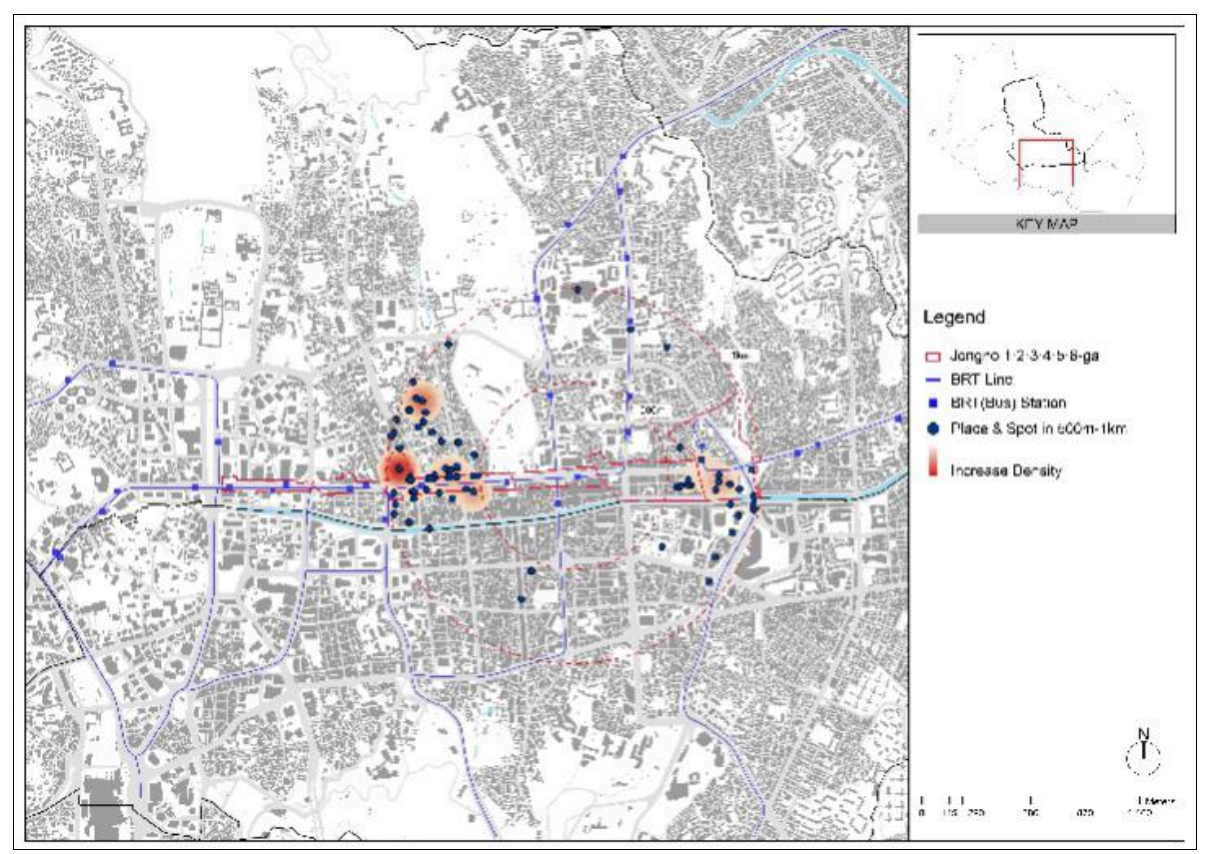

Frequency Increase in Areas Located within $500 \mathrm{~m}$ to $1 \mathrm{~km}$

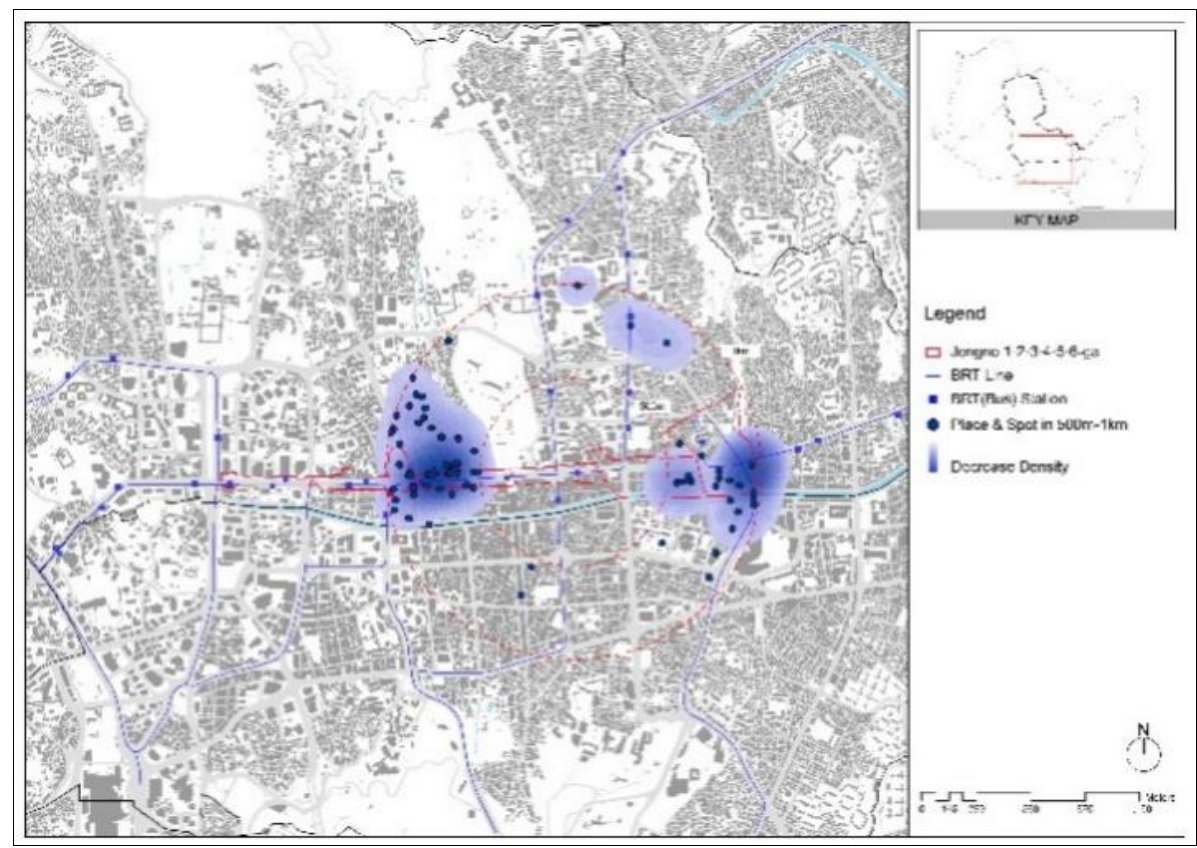

Frequency decrease in areas located within $500 \mathrm{~m}$ to $1 \mathrm{~km}$

Figure 6. Frequency variations of places according to $500 \mathrm{~m}-1 \mathrm{~km}$ distance from the station

Compared to the 500-m radius, there was an increase in keyword frequency for commercial buildings located within a $1-\mathrm{km}$ radius of the BRT station. Hence, the provision of a new mode of transport after the construction of the BRT station improved visitors' accessibility to their destinations, and the activity radius varied depending on each visitor's purpose and behaviour. For example, one user wrote, "For my mum, who loves street food, I stopped by Gwangjang Market on the other side of the 
street to buy Korean-style pancakes and Mayak (addictive) Gimbap and walked to Jongno's 4th Street to get on the bus" (Document 569). Reflecting on the benefits of using the BRT system compared to those of driving, one user explained, "As we still did not have matching couple's rings, we excitedly headed to Jongno's 4th Street (Jongmyo Shrine) thanks to the direct bus route from home! We did not dare to drive there, because it is so difficult to park" (Document 980). Similarly, another visitor compared the BRT to the metro system as follows: "I could have taken the metro, but by taking the bus, I could enjoy the city views and leisurely arrive at YongsanJongno's 4th Street" (Document 1106).

By analysing keyword frequencies, we demonstrated that a BRT station can improve an area's accessibility by providing visitors with a convenient mode of transport. An increase in the number of users of public transport causes an increase in pedestrian flow, the number of visitors to the area and the exposure of significant places. This further increases visits to local tourist attractions and commercial districts and helps invigorate the local community. Nevertheless, the impact of BRT stations can be either positive or negative, depending on a particular location's distance from the station, the purposes of visitors' visits and the users' behaviour.

\section{CONCLUSIONS}

The aim of this study was to investigate how users perceive the active utilisation of public transport following the opening of a BRT system. For this purpose, we used a text mining method to analyse blog posts on places near Jongno Street, where the BRT project was implemented. Based on a combination of keyword analyses and text mining, in this study we categorised the frequently visited places and points on Jongno Street and examined the changes in user behaviours by analysing keyword frequencies before and after the project's implementation. We found a total of 276 significant places on Jongno Street and identified nine types of spaces. Each of Jongno's streets offered a different experience to BRT users related to various purposes, while representing common usage areas, such as commercial and business facilities, historic sites, and landmarks.

The findings revealed changes in user behaviours after the introduction of the BRT system. For places located within a $500-\mathrm{m}$ radius from the BRT station, the frequency of place keywords increased in the categories of historic sites, and commercial and business facilities. However, the frequency decreased in other categories, contrary to the findings of earlier studies, since the BRT station increased visitors' direct accessibility to their destinations. Regarding the places located outside the 500-m radius, the place keyword frequency increased in the following categories characterised by foot traffic: open spaces, major places, cultural and religious places, and streets. The keyword frequency for nearby commercial and business facilities, such as restaurants and cafes, was also found to have increased. The scope of visitors' activities increased within a radius of $1 \mathrm{~km}$ from the station.

The study revealed that BRT users walk to their destinations. This demonstrates that public transport can transform Seoul into a vigorous and walkable city. Furthermore, the implementation of BRT directly provided a convenient mode of transport for visitors and increased the accessibility of destinations. This caused an increase in the number of visitors and in pedestrian flow, and promoted the commercial district's expansion by 
increasing the exposure of the area's significant places. Further, text analysis offers a larger sample size and more comprehensive interpretations than conventional survey research. By analysing the perspectives of general users, as opposed to those of experts, the study revealed visitors' experiences and enabled us to understand and visualise place types, visitors' perceptions and behavioural changes, and the scope of such behavioural changes.

Based on the results regarding the impact of BRT on neighbouring areas, we conclude that there is a need to meticulously analyse the entire BRT project from the planning phase to the connecting phase. Integrating a BRT metropolitan transport system with individual transport systems will provide significant convenience and management sustainability in the urban space and improve people's quality of life.

Nevertheless, the study has some limitations. Although we this study analysed the volume of place keywords within blog posts, it did not employ a sensitivity analysis or perform field verifications. Moreover, it is difficult to generalise the findings of this study since the target area was a long, busy street that houses commercial, business and public facilities. In particular, Jongno Street is an area that contains some business headquarters, which demands the implementation of a BRT system. Hence, future studies should include an analysis of the effect of implementing BRT systems in suburbs and residential districts on the residents' community and facilities.

\section{REFERENCES}

Bocarejo S., J. P., \& Oviedo H., D. R. (2012). “Transport Accessibility and Social Inequities: A Tool for Identification of Mobility Needs and Evaluation of Transport Investments". Journal of Transport Geography, 24, 142-154. doi: https://doi.org/10.1016/j.jtrangeo.2011.12.004.

Bregman, S. (2012). Uses of Social Media in Public Transportation. Transportation Research Board.

Casas, I., \& Delmelle, E. C. (2017). "Tweeting about Public Transit - Gleaning Public Perceptions from a Social Media Microblog". Case Studies on Transport Policy, 5(4),634 642. doi: https://doi.org/10.1016/i.cstp.2017.08.004.

Cervero, R., \& Dai, D. (2014). "BRT TOD: Leveraging Transit Oriented Development with Bus Rapid Transit Investments". Transport Policy, 36, 127-138. doi: https://doi.org/10.1016/j.tranpol.2014.08.001.

Cervero, R., \& Kang, C. D. (2011). "Bus Rapid Transit Impacts on Land Uses and Land Values in Seoul, Korea". Transport Policy, 18(1), 102-116. doi: https://doi.org/10.1016/j.tranpol.2010.06.005.

Chan, R., \& Schofer, J. L. (2014). "Role of Social Media in Communicating Transit Disruptions". Transportation Research Record, 2415(1), 145-151. doi: https://doi.org/10.3141/2415-16.

Chang, Z., Chen, J., Li, W., \& Li, X. (2019). "Public Transportation and the Spatial Inequality of Urban Park Accessibility: New Evidence from Hong Kong". Transportation Research Part D: Transport and Environment, 76, 111-122. doi: https://doi.org/10.1016/j.trd.2019.09.012.

Collins, C., Hasan, S., \& Ukkusuri, S. V. (2013). "A Novel Transit Rider Satisfaction Metric: Rider Sentiments Measured from Online Social Media Data". Journal of Public Transportation, 16(2), 21-45. doi: https://doi.org/10.5038/2375-0901.16.2.2.

Combs, T. S., \& Rodríguez, D. A. (2014). "Joint Impacts of Bus Rapid Transit and Urban Form on Vehicle Ownership: New Evidence from a Quasi-Longitudinal Analysis in Bogotá, Colombia”. Transportation Research Part A: Policy and Practice, 69, 272-285. doi: https://doi.org/10.1016/j.tra.2014.08.025.

Daniel, B. (2015). "Big Data and Analytics in Higher Education: Opportunities and Challenges". British Journal of Educational Technology, 46(5), 904-920. doi: https://doi.org/10.1111/bjet.12230. 
Deng, T., \& Nelson, J. D. (2011). "Recent Developments in Bus Rapid Transit: A Review of the Literature". Transport Reviews, 31(1), 69-96. doi: https://doi.org/10.1080/01441647.2010.492455.

Dimitriou, H. T., \& Gakenheimer, R., Eds. (2011). Urban Transport in the Developing World: A Handbook of Policy and Practice. Cheltenham and Northampton: Edward Elgar Publishing.

Elhajj, M., \& Ochieng, W. Y. (2020). "Urban Bus Positioning: Location Based Services and High Level System Architecture”. Case Studies on Transport Policy, 8(1), 12-21. doi: https://doi.org/10.1016/j.cstp.2020.01.004.

Gal-Tzur, A., Grant-Muller, S. M., Minkov, E., \& Nocera, S. (2014). "The Impact of Social Media Usage on Transport Policy: Issues, Challenges and Recommendations". Procedia Social and Behavioral Sciences, 111, 937-946. doi: https://doi.org/10.1016/j.sbspro.2014.01.128.

Grant-Muller, S. M., Gal-Tzur, A., Minkov, E., Kuflik, T., Nocera, S., \& Shoor, I. (2015). "Transport Policy: Social Media and User-Generated Content in a Changing Information Paradigm”. In Nepal, S., Paris, C., and Georgakopoulos, D. (Eds.), Social Media for Government Services (pp. 325-366). New York: Springer.

Guo, L., Vargo, C. J., Pan, Z., Ding, W., \& Ishwar, P. (2016). "Big Social Data Analytics in Journalism and Mass Communication: Comparing Dictionary-Based Text Analysis and Unsupervised Topic Modeling”. Journalism \& Mass Communication Quarterly, 93(2), 332-359. doi: https://doi.org/10.1177/1077699016639231.

Hannigan, T. (2015). "Close Encounters of the Conceptual Kind: Disambiguating Social Structure from Text”. Big Data \& Society, 2(2), 2053951715608655. doi: https://doi.org/10.1177/2053951715608655.

Hotho, A., Nürnberger, A., \& Paass, G. (2005). “A Brief Survey of Text Mining”. Ldv Forum, $20,19-62$.

Jackson, R., Kahsai, M., Schaeffer, P., Middleton, M., \& Yu, J. (2015). “A Framework for Measuring County Economic Resilience”. Regional Research Institute, West Virginia University Working Papers.

Jang, H.-M., Kim, E.-M., \& Rhee, J.-W. (2012). "The Effects of Blog Writing for SelfPresentation and Preference toward Others' Blog Writing for Self-Presentation on Interpersonal and Social Trust: Focusing on the Mediating Effects of Empathic Experiences of Blog Use". Korean Journal of Journalism \& Communication Studies, $56(2), 48-71$.

Jun, M.-J., Choi, K., Yu, J. W., \& Chung, W. (2015). "Bus Patronage Change after Sustainable Bus Reform: A Nested Logit Approach with the Case of Seoul”. International Journal of Sustainable Transportation, 9(7), 520-528. doi: https://doi.org/10.1080/15568318.2013.814078.

Karl, A., Wisnowski, J., \& Rushing, W. H. (2015). “A Practical Guide to Text Mining with Topic Extraction". WIREs Computational Statistics, 7(5), 326-340. doi: https://doi.org/10.1002/wics.1361.

Knowles, R. D. (2012). "Transit Oriented Development in Copenhagen, Denmark: From the Finger Plan to Ørestad". Journal of Transport Geography, 22, 251-261. doi: https://doi.org/10.1016/j.jtrangeo.2012.01.009.

Lee, J.-H., \& Chung, H.-S. (2014). "Producing and Consuming Landscape Images Via Social Media Blogs: The Case of Seochon, Seoul". Journal of the Korean Urban Geographical Society, 17(3), 123-140.

Lee, S.-H., \& Son, Y.-H. (2018). "Identifying Landscape Perceptions of Visitors' to the Taean Coast National Park Using Social Media Data - Focused on Kkotji Beach, Sinduri Coastal Sand Dune, and Manlipo Beach". Journal of the Korean Institute of Landscape Architecture, 46(5), 10-21. doi: https://doi.org/10.9715/kila.2018.46.5.010.

Levinson, H. S., Zimmerman, S., Clinger, J., \& Gast, J. (2003). "Bus Rapid Transit: Synthesis of Case Studies". Transportation Research Record, 1841(1), 1-11. doi: https://doi.org/10.3141/1841-01.

Lim, H., \& Park, S. (2015). "A Tentative Approach for Regional Futures Strategy with Big Data-Through the Analysis Using the Data of SNS and Newpaper". Journal of The Korean Cadastre Information Association, 17, 75-90.

Lucas, C., Nielsen, R. A., Roberts, M. E., Stewart, B. M., Storer, A., \& Tingley, D. (2015). "Computer-Assisted Text Analysis for Comparative Politics". Political Analysis, 23(2), 254-277. doi: https://doi.org/10.1093/pan/mpu019.

Mahmoudi, R., Shetab-Boushehri, S.-N., Hejazi, S. R., \& Emrouznejad, A. (2019). "Determining the Relative Importance of Sustainability Evaluation Criteria of Urban Transportation Network". Sustainable Cities and Society, 47, 101493. doi: https://doi.org/10.1016/j.scs.2019.101493. 
Matthies, B., \& Coners, A. (2015). "Computer-Aided Text Analysis of Corporate Disclosures - Demonstration and Evaluation of Two Approaches". The International Journal of Digital Accounting Research, 15, 69-98.

Moreno, A., \& Redondo, T. (2016). "Text Analytics: The Convergence of Big Data and Artificial Intelligence". International Journal of Interactive Multimedia and Artificial Intelligence, 3(6), 57-64.

Mulley, C., \& Tsai, C.-H. (Patrick). (2016). "When and How Much Does New Transport Infrastructure Add to Property Values? Evidence from the Bus Rapid Transit System in Sydney, Australia". Transport Policy, 51, 15-23. doi: https://doi.org/10.1016/j.tranpol.2016.01.011.

Rodríguez, D. A., \& Mojica, C. H. (2009). "Capitalization of BRT Network Expansions Effects into Prices of Non-Expansion Areas". Transportation Research Part A: Policy and Practice, 43(5), 560-571. doi: https://doi.org/10.1016/j.tra.2009.02.003.

Rodríguez, D. A., \& Targa, F. (2004). "Value of Accessibility to Bogotá's Bus Rapid Transit System". Transport Reviews, 24(5), 587-610. doi: https://doi.org/10.1080/0144164042000195081.

Salon, D., Wu, J. (Dora), \& Shewmake, S. (2014). "Impact of Bus Rapid Transit and Metro Rail on Property Values in Guangzhou, China". Transportation Research Record, 2452(1), 36-45. doi: https://doi.org/10.3141/2452-05.

Thomas, A., \& Deakin, E. (2008). "Land Use Challenges to Implementing Transit-Oriented Development in China: Case Study of Jinan, Shandong Province". Transportation Research Record, 2077(1), 80-86. doi: https://doi.org/10.3141/2077-11.

Wegener, M. (2011). "Transport in Spatial Models of Economic Development". in A. de Palma, R. Lindsey, E. Quinet, and R. Vickerma (Eds.), A Handbook of Transport Economics. Cheltenham: Edward Elgar Publishing.

Wirasinghe, S. C., Kattan, L., Rahman, M. M., Hubbell, J., Thilakaratne, R., \& Anowar, S. (2013). "Bus Rapid Transit - a Review". International Journal of Urban Sciences, 17(1), 1-31. doi: https://doi.org/10.1080/12265934.2013.777514.

Zakir, J., Seymour, T., \& Berg, K. (2015). "Big Data Analytics". Issues in Information Systems, 16(2), 81-90. 